\title{
Fluidized bed combustion of sawdust pellets
}

\author{
Mario Matiauda ${ }^{1}$, Juan B. de León Benítez ${ }^{2}$, Nora Freaza1, Marta Rivero ${ }^{1}$ \\ ${ }^{1}$ Universidad Nacional de Misiones, Posadas, Argentina \\ *2Dpto de ingeniería Química. Facultad de Química Farmacia. Universidad Central \\ de Las Villas; Carretera a Camajuaní km 5 y 1/2, Santa Clara, Villa Clara, Cuba. \\ *Correspondencia autores:J.B. de Leon:Tel.0534221528;juanba@uclv.edu.cu, M. Matiauda: matiauda@unam.edu.ar N.Freaza: \\ freaz@unam.edu.ar;M.Rivero: rivero@unam.edu.ar
}

\begin{abstract}
The combustion in bed fluidized appear with good perspectives inside the technological options for the energetic availability from a fuel, given his flexibility as regards the fuels to employ like his possibilities of clean operation and efficient, beside the possibility of change of scale. In this article expose the results achieved to scale of pilot plant of the operation of a reactor of bed fluidized in the combustion of pellets of sawdust with views to his application in the exploitation of the solid waste in the process of production of bioethanol of lignocelulosicos.
\end{abstract}

Key-words: combustion- sawdust - bed fluidized

\section{Combustión en lecho fluidizado de pellets de aserrín}

\section{RESUMO}

La combustión en lecho fluidizado aparece con buenas perspectivas dentro de las opciones tecnológicas para la disponibilidad energética a partir de un combustible, dada su flexibilidad respecto a los combustibles a emplear como sus posibilidades de operación limpia y eficiente, junto a la posibilidad de cambio de escala. En este artículo se exponen los resultados alcanzados a escala de planta piloto del funcionamiento de un reactor de lecho fluidizado en la combustión de pellets de aserrín con vistas a su aplicación en el aprovechamiento de los residuos sólidos en el proceso de producción de bioetanol de lignocelusicicos.

Palabras claves: combustión-aserrín-lecho fluidizado

\section{INTRODUCCIÓN}

La combustión en lecho fluidizado es un proceso por el cual se convierte un lecho de partículas en estado fluido por medio de una corriente ascendente de gas o líquido.

Al estar expuesto, un lecho fijo de partículas, a una corriente gaseosa ascendente, las partículas individualmente tienden a separarse, iniciando la expansión del lecho. Las partículas se mueven erráticamente con una rápida transferencia de calor en el lecho a pesar de la baja conductividad térmica de gas y partículas, fenómeno extensivo a la transferencia de masa de gas-partículas. El movimiento resulta en un mezclado total y estacionario de los materiales del lecho, con una temperatura de lecho homogénea, aún cuando se dieran procesos fuertemente exo o endotérmicos. Los sólidos están bien expuestos a la fase gas [1].

La temperatura de combustión está afectada por la velocidad de alimentación del combustible, el contenido de humedad del combustible, la velocidad de alimentación del aire primario o de fluidización, el valor calorífico del combustible, la temperatura de precalentamiento del combustible. El lecho burbujeante es un reactor virtualmente de mezcla total e isotérmico, operando como un contactor gas-sólido donde los sólidos se mezclan permanentemente por el efecto de fluidización, pudiendo establecerse que las partículas sólidas se queman en el lecho mientras los volátiles lo hacen sobre el lecho [2]. 
Mario Matiauda , *Juan B. de León Benítez , Nora Freaza1, Marta Rivero / ITEGAM-JETIA Vol.01, Nº 01, pp.55-60. Março, 2015.

En el presente artículo se resume el estudio de la combustión de pellets de aserrín en lecho fluidizado que incluye el análisis de las características del cambio de tamaño del combustible en el proceso y posible influencia sobre los parámetros de velocidad y tiempo de combustión, trabajándose con dos especies maderables claramente distinguibles: pino elliottii y palo blanco.

\section{DESARROLLO}

\section{Modelo de combustión.}

El modelo teórico estudia la combustión y liberación de materia volátil de un pellet de madera de geometría cilíndrica, en lecho fluidizado, bajo condiciones predeterminadas de operación. El modelo permite determinar el tiempo de liberación de materia volátil, etapa de devolatilización o pirólisis primaria. La materia residual carbonizada (char) se modeliza en base al comportamiento de una partícula que combustiona a densidad constante (Scala, 2006). Físicamente se distinguen tres secciones en la unidad: lecho, zona de salpicado y zona libre; el lecho se considera isotérmico; la temperatura del lecho se toma como variable de diseño; la partícula pelletizada se considera homogénea; el material de combustión consiste básicamente en materia volátil, carbono fijo y cenizas; el char sólo contiene carbono fijo y cenizas; la materia volátil se quema fuera de la superficie del lecho, pirólisis secundaria; los productos gaseosos intervienen en reacciones secundarias, una vez que dejan el lecho, a medida que se producen [3][4][5][6].

La combustión en el lecho es gobernada por la transferencia de calor (perfil térmico descripto por ecuación de conducción en modelo bidimensional) y la cinética del proceso de combustión sigue el modelo de Arrhenius con orden uno. Se distinguen dos etapas, desarrolladas secuencialmente: a) devolatilización b) combustión de la partícula residual (char). La primera etapa corresponde al modelo de partícula encogiéndose a densidad constante, en un rango de temperatura superior a $500{ }^{\circ} \mathrm{C}$ y corresponde a la pirólisis primaria; el pellet se degrada térmicamente desprendiendo gran cantidad de materia volátil, con transferencia de calor hacia el pellet. Los factores que influyen sobre la devolatilización: diámetro de la partícula de material combustible, temperatura del lecho, cantidad de oxígeno en el gas fluidizante, velocidad superficial del gas, diámetro principal de partícula del lecho y contenido de humedad del combustible [7][8]. La segunda etapa, de combustión del char, se apoya en el modelo del núcleo encogiéndose (disminución de densidad, diámetro de la partícula constante) y modelo de partícula encogiéndose (densidad constante, disminución de diámetro), este último el más apropiado para material maderable.

\section{Equipamiento utilizado}

Reactor tubular de $45 \mathrm{~mm}$ de diámetro y $1 \mathrm{~m}$ de alto con cámara de aislamiento térmica de fibra cerámica, cubierta de chapa DDN 18 terminado con epoxi. Posee además una termocupla de indicación, debajo de placa de distribución de gases. Las termocuplas, conectadas a un equipo controlador programable de temperaturas, son de tipo $\mathrm{K}$ envainadas, la calefacción se efectúa por tres cilindros concéntricos al tubo reactor, construidos en resistencias de masa embutimiendo.

El reactor y equipo de control se instalaron en la planta piloto de la Facultad de Ciencias Exactas, Químicas y Naturales (UNaM), instalándose también el circuito de potencia para su alimentación eléctrica así como el set de termocuplas para la medición de temperaturas, figura 1.

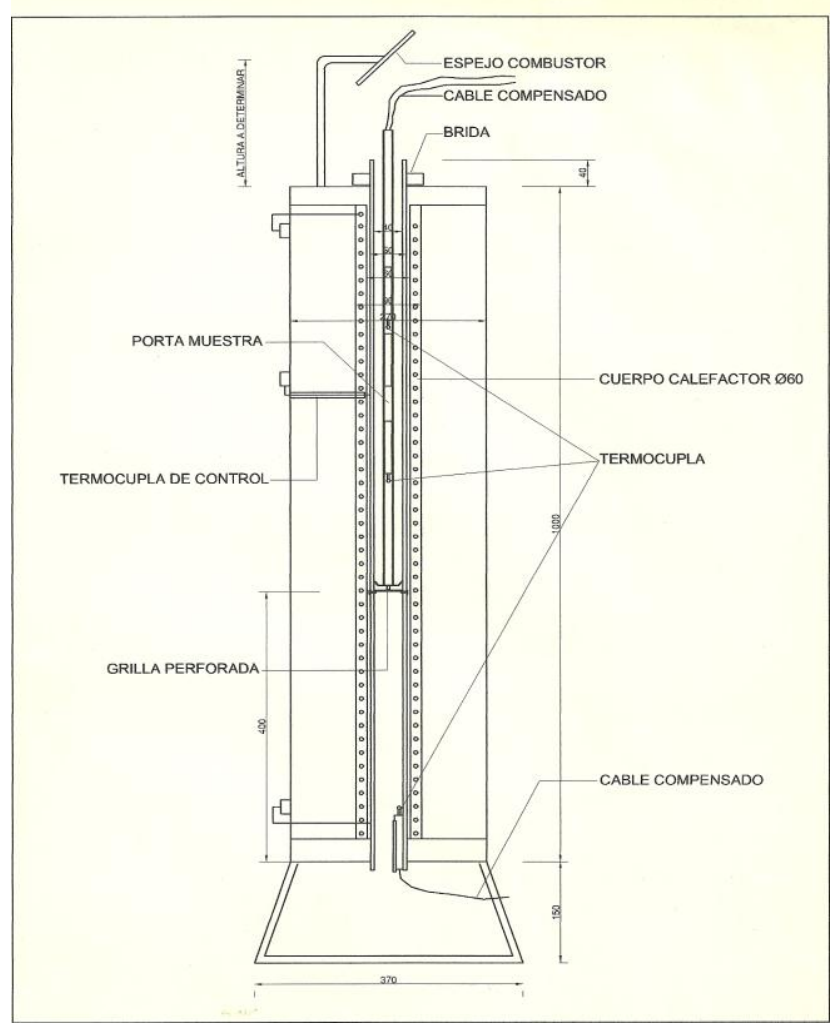

Figura 1. Diagrama del reactor tubular empleado en las experiencias

\section{PARTE EXPERIMENTAL}

\section{Preparación de las muestras.}

Se trabajó con muestras de pino y de palo blanco, de geometría cilíndrica y diámetro $d_{p}(\mathrm{~mm})$ promedio variando en un rango de $10 \mathrm{~mm}$ a $12 \mathrm{~mm}$, tabla 1 . 
Mario Matiauda , *Juan B. de León Benítez, Nora Freaza1, Marta Rivero / ITEGAM-JETIA Vol.01, Nº 01, pp.55-60. Março, 2015.

Tabla 1. Dimensiones de las muestras

\begin{tabular}{|c|c|}
\hline$d p(\mathrm{~mm})$ & $L(\mathrm{~mm})$ \\
\hline 12 & 24 \\
\hline 12 & 18 \\
\hline 10 & 18 \\
\hline
\end{tabular}

\section{Acondicionamiento del lecho}

Para condiciones adecuadas de fluidización, se usó lecho de arena de granulometría media $(0.42 \mathrm{~mm})$, contenidos de humedad y porosidad controlados; altura media del lecho sin expandir, de 3 a $3.2 \mathrm{~cm}$; inyección de aire con soplador, a velocidad constante, sin modificar la concentración de oxígeno en aire entrante. La temperatura del lecho se mantuvo aproximadamente en un rango de $800^{\circ} \mathrm{C}$ a $850{ }^{\circ} \mathrm{C}$.

\section{Estudio de la fragmentación primaria en la etapa de} devolatilización.

Tiempo de devolatilización.

\section{Pruebas en el reactor}

Se realizaron varias pruebas para determinar el tiempo de liberación de materia volátil $\left(t_{v}\right)$, con el fin de caracterizar la etapa de devolatilización, a la cual se refiere la fragmentación primaria, tomando muestras individuales. El tiempo $\left(t_{v}\right)$ fue determinado por observación visual desde la boca superior de la columna de fluidización, en el reactor. Durante la devolatilización, el cilindro de madera giraba, flotando suspendido en el lecho fluidizado, mostrando un aspecto brillante, incandescente, con desprendimiento de volátiles.

Se determinó el tiempo $\left(t_{v}\right)$ al observarse ignición (formación de llama), induciendo la formación de coke y posterior oscurecimiento de la muestra, con decrecimiento gradual de tamaño, tabla 2.

Tabla 2- Tiempos de devolatilización $\left(t_{v}\right)$ (pino)

\begin{tabular}{|c|c|}
\hline$d p / L(\mathrm{~mm})$ & $t_{v}(\mathrm{~s})$ \\
\hline $12 / 24$ & 47 \\
\hline $12 / 24$ & 60 \\
\hline $12 / 18$ & 58 \\
\hline $10 / 18$ & 45 \\
\hline
\end{tabular}

Se realizaron pruebas similares a la descripta anteriormente, teniendo en cuenta los mismos parámetros y condiciones de operación, para muestras obtenidas con varillas de palo blanco, densidad: 860,0 $\left(\mathrm{kg} / \mathrm{m}^{3}\right)$ y contenido de humedad: 15 (\% peso), tabla 3

Tabla 3- Tiempos de devolatilización $\left(t_{v}\right)$ (palo blanco)

\begin{tabular}{|c|c|}
\hline$d p / L(\mathrm{~mm})$ & $t_{v}(\mathrm{~s})$ \\
\hline $12 / 24$ & 68 \\
\hline $12 / 24$ & 67 \\
\hline $10 / 18$ & 47 \\
\hline
\end{tabular}

\section{RESULTADOS TEÓRICOS Y EXPERIMENTALES.}

i) Para los tiempos de devolatilización teóricos, se utilizó una relación de la forma:

$$
t_{v}=\lambda_{v}(d p)^{\phi}
$$

En la que el tiempo de liberación de volátiles $\left(t_{v}\right)$ está dado en términos del diámetro de la muestra $(d p)$ y los parámetros $\left(\lambda_{v}\right)$ constante de proporcionalidad y $(\phi)$, exponente en la función potencial. La constante de devolatilización $\left(\lambda_{v}\right)$ depende del tipo de combustible y de la temperatura del lecho.

La determinación de $\left(\lambda_{v}\right)$ y de $(\phi)$ se efectúa en ajuste con los valores experimentales (gráfico) y/o tabla de valores como aparece en la tabla 4.

Tabla 4- valores experimentales de Tiempos de $\left(\lambda_{v}\right)$ y $(\phi)$

\begin{tabular}{|c|c|c|c|c|c|c|c|c|c|}
\hline $\begin{array}{c}\text { Temperatura } \\
\text { del } \\
\text { Lecho }\left({ }^{\circ} \mathrm{K}\right)\end{array}$ & \multicolumn{2}{|c|}{$873-923$} & \multicolumn{3}{|c|}{$973-1073$} & \multicolumn{3}{|c|}{$1073-1103$} \\
\hline $\begin{array}{c}\text { Pellet }\left({ }^{d_{p}}\right. \\
(\mathrm{mm})\end{array}$ & 10 & 8 & 6 & 10 & 8 & 6 & 10 & 8 & 6 \\
\hline$\lambda_{v}$ & \multicolumn{2}{|c|}{1.9} & \multicolumn{2}{|c|}{1.7} & \multicolumn{3}{|c|}{1.5} \\
\hline$\phi$ & \multicolumn{2}{|c|}{1.01} & \multicolumn{2}{|c|}{1.08} & \multicolumn{2}{|c|}{1.1} \\
\hline
\end{tabular}

Se compararon los tiempos obtenidos para pellets compactados de aserrín de pino y muestras cilíndricas obtenidas de varillas de pino, utilizando la correlación dada por la ecuación (1), así como también los tiempos teóricos y medidos para las muestras cilíndricas, como se muestra en la figura 2. 
Mario Matiauda , *Juan B. de León Benítez , Nora Freaza1, Marta Rivero / ITEGAM-JETIA Vol.01, Nº 01, pp.55-60. Março, 2015.

Utilizando el valor de $\phi=1.1\left(\mathrm{~T}_{1}=800{ }^{\circ} \mathrm{C}\right)$, estimado para la combustión de pellets, se obtiene un valor del parámetro $\lambda_{v}=3.6\left[\mathrm{~s} / \mathrm{mm}^{\phi}\right]\left(\mathrm{T}_{1}=830^{\circ} \mathrm{C}\right)$, para las muestras cilíndricas.

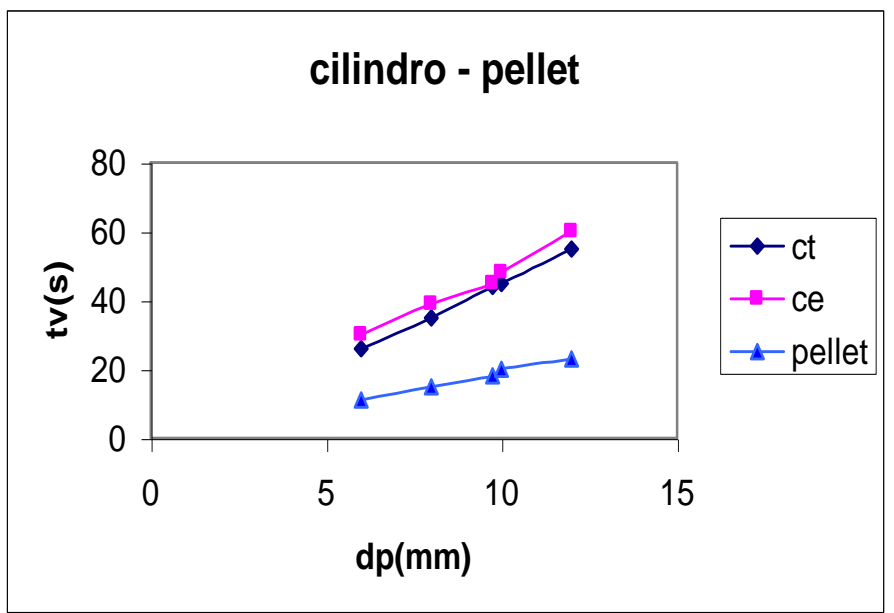

Figura 2. Comparación de los tiempos de desvolatilizacion donde ct $=$ cilindro (tiempo teórico) y ce $=$ cilindro (tiempo experimental)

\section{Sobre la fragmentación primaria}

En esta etapa de devolatilización, se realizó la extracción de muestra residual y posterior evaluación de tipo y número de fragmentos obtenidos.

\section{a) Pino}

El residuo post-devolatilización consistió en un cilindro de dimensiones reducidas, generando muy pocos fragmentos. Un ejemplo se muestra en la tabla 5.

Tabla 5- Dimensiones del cilindro que conforma el residuo de la post desvolatilizacion

\begin{tabular}{|c|c|c|}
\hline$d p / L(\mathrm{~mm})$ & $d p^{*}(\mathrm{~mm})$ & $L^{*}(\mathrm{~mm})$ \\
\hline $12 / 24$ & $9,5-10$ & 18 \\
\hline
\end{tabular}

\section{b) Palo blanco}

Para una temperatura del lecho $T_{l}=820^{\circ} \mathrm{C}$, los residuos obtenidos en la etapa de devolatilización presentaron características particulares con relación a los obtenidos para las muestras de pino.

En general, el cilindro residual no conservó su estructura, es decir, produjo un número mayor de fragmentos, de dimensiones variables.
Se observaron también diferencias en el aspecto y consistencia de los residuos de una y otra muestra. Los residuos de pino devolatilizados se mostraron sólidos, como "carbones", presentando una coloración de marrón oscuro a negro; los de palo blanco, en cambio, resultaron blanquecinos y de consistencia frágil, similar a la ceniza como se muestra en la figuras 3 y 4 .

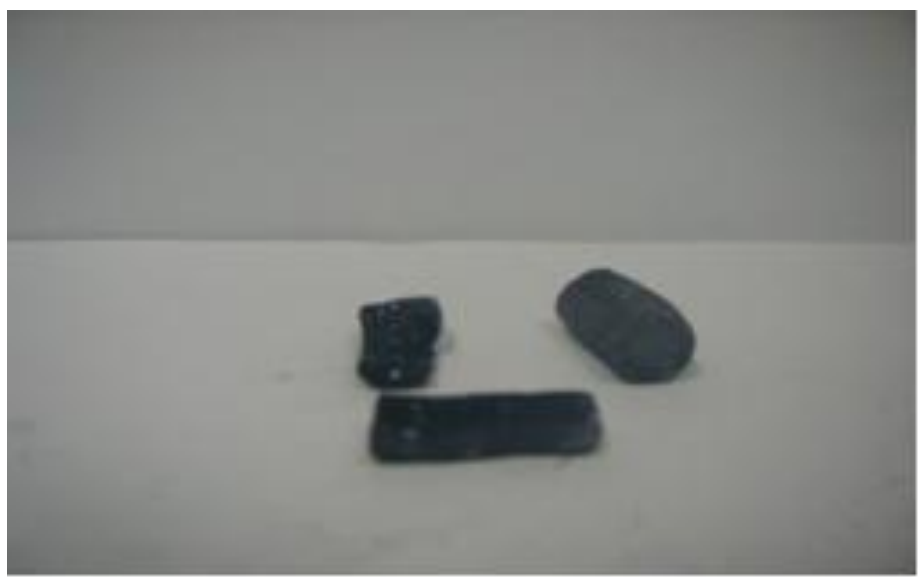

Figura 3: Residuo de pino

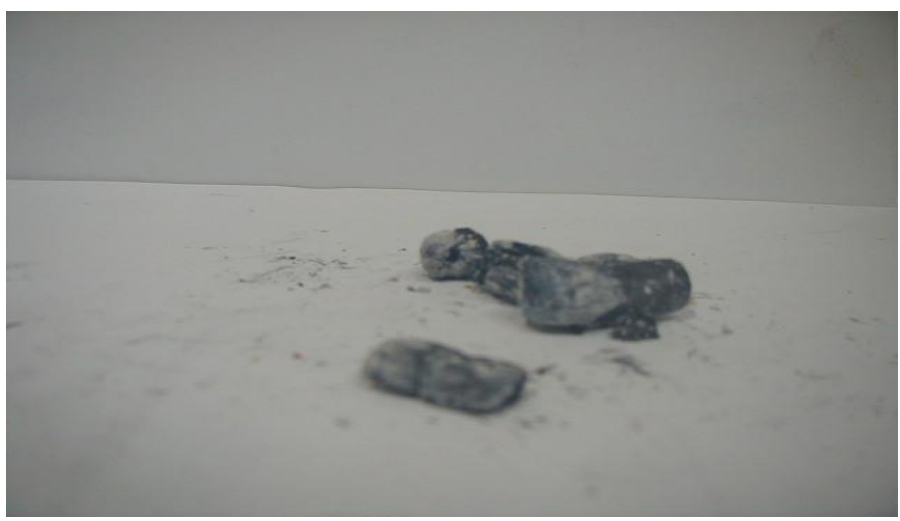

Figura 4: Residuo de palo blanco.

\section{c) Evolución térmica en la etapa}

Se compararon las evoluciones térmicas para muestras de pino y palo blanco. Para ello se suspendieron los cilindros de ambas muestras en el lecho fluidizado a $\left(T_{l}=820^{\circ} \mathrm{C}\right)$ mediante termocupla dispuesta en sentido longitudinal, en coincidencia con el centro de la muestra; se registraron las temperaturas durante la etapa de devolatilización, figura 5.

Se realizaron idénticas pruebas en el reactor, sin lecho fluidizado, usando muestras de pino y de palo blanco $d p / L=12$ $124 \mathrm{~mm}$, con el fin de determinar el tiempo de devolatilización y caracterizar el residuo devolatilizado, figura 6. 
Mario Matiauda , *Juan B. de León Benítez , Nora Freaza1, Marta Rivero / ITEGAM-JETIA Vol.01, Nº 01, pp.55-60. Março, 2015.

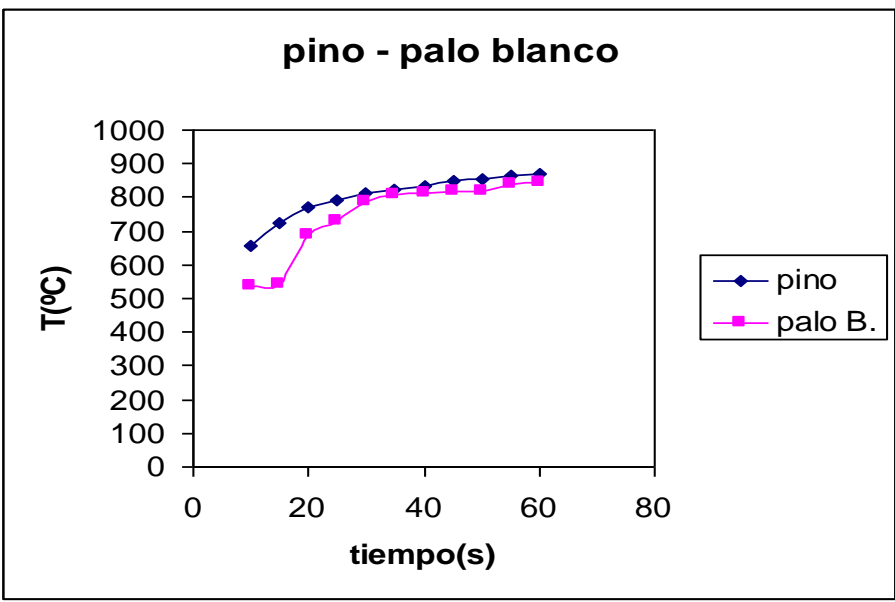

Figura 5. Resultados de evaluaciones térmicas para muestras de pino y palo blanco en el lecho fluidizado a $\left(T_{l}=820^{\circ} \mathrm{C}\right)$ en función del tiempo.

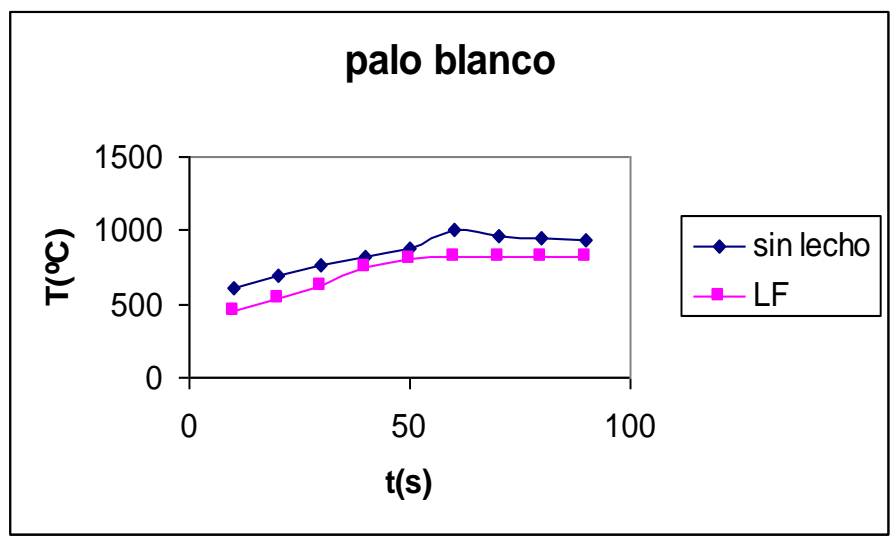

Figura 6. Resultados de evaluaciones térmicas para muestras de pino y palo blanco sin lecho fluidizado a $\left(T_{l}=820^{\circ} \mathrm{C}\right)$ en función del tiempo.

\section{Cuantificación del fenómeno de fragmentación primaria}

La fragmentación primaria ocurre en forma inmediata al alimentar las muestras combustibles poniéndolas en contacto con el lecho fluidizado, dentro de la columna de fluidización del reactor, debido al corto tiempo transcurrido para devolatilizar la partícula combustible, frente al tiempo necesario para la combustión del "char", asociado a la fragmentación secundaria.

Los resultados de la fragmentación primaria, para las dos muestras usadas, se expresan por medio de los siguientes indicadores:

- $\quad \boldsymbol{p}_{f}$, que mide la probabilidad de fragmentación primaria; representa el número de fragmentos generado por unidad de partículas combustibles que sufren fragmentación al devolatilizar, dividido por el número total de partículas alimentadas.

- $f_{1}$, factor de multiplicación de fragmentación primaria; representa el número de fragmentos generados por unidad de partículas combustibles alimentadas al reactor.

- $\boldsymbol{d}_{\boldsymbol{p}}{ }^{*}$, diámetro medio de las partículas de char después de la devolatilización.

\section{Resultados}

Se trabajó con grupos de muestras, tanto de pino como de palo blanco, alimentándolas al reactor en varias corridas regulares, en lecho fluidizado durante el tiempo $t_{v}(\mathrm{~s})$.

En general, los residuos devolatilizados presentaron características disímiles, tratándose de pino o de palo blanco. En el primer caso, el coke devolatilizado se mostró entero en sus tres cuartas partes; en tanto que el palo blanco, se mostró fragmentado.

La tabla 6 registra los resultados de los experimentos de la fragmentación primaria

Tabla 6- Resultados de la fragmentación primaria

\begin{tabular}{|c|c|c|c|}
\hline Muestra & $\boldsymbol{f}_{\boldsymbol{l}}$ & $\boldsymbol{d} \boldsymbol{p}(\mathrm{mm})$ & $\boldsymbol{d}_{\boldsymbol{p}} *(\mathrm{~mm})$ \\
\hline Pino & 1,45 & $10-12$ & $9,5-10$ \\
\hline Palo blanco & 2 & $10-12$ & $6-8,5$ \\
\hline
\end{tabular}

Donde:

$\boldsymbol{d p}$, diámetro inicial de las partículas alimentadas ( $\mathrm{mm})$ $\boldsymbol{d}_{p}{ }^{*}$, diámetro medio de partículas devolatilizadas (mm) $\boldsymbol{p}_{f}$, probabilidad de fragmentación primaria (-) $f_{1}$, factor de multiplicación de fragmentación primaria (-).

\section{CONCLUSIONES}

La fragmentación primaria ha sido estudiada registrando el número y tamaño de partículas producidas por la muestra combustible después de la devolatilización.

Las muestras de pino experimentaron fragmentación moderada dando un factor de multiplicación $f_{l}$ aproximadamente igual a 1,45 . Esto lleva a una reducción del diámetro medio, que podría ocurrir inmediatamente después de inyectar las partículas combustibles en el lecho fluidizado como consecuencia de las tensiones térmicas y sobretensiones provocadas por la liberación 
Mario Matiauda , *Juan B. de León Benítez , Nora Freaza1, Marta Rivero / ITEGAM-JETIA Vol.01, Nº 01, pp.55-60. Março, 2015. de materia volátil; pero, también, esta reducción podría deberse al encogimiento particular.

En el caso del palo blanco la fragmentación se cuantifica por un $f_{1}$ aproximadamente igual a 2 o mayor y una $p_{f}$, también mayor, con relación al pino.

En general, se produce una reducción radial, próxima al $21 \%$ en las muestras de pino y algo mayor, para palo blanco, evidenciándose este aspecto después de la devolatilización.

\section{5 . REFERENCIAS BIBLIOGRAFICAS}

[1] Saxena,S.C; Joshi,C.K.. "Fluidized bed icineration of waste materials" Progress in Energy and combustion Science, 1994.

[2] Anthony, F. J. "Fluidized bed combustion of alternative solid fuels: status, success and problems of the technology". Progress in Energy and Combustion Science,1995.

[3] Scala,F; Salatino,P. "Modelling fluidized bed combustion of high-volatile solid fuels". Chemical Engineering Science. No. 57. pp. 1175-1196, 2002.

[4] Scala,F; Chirone, R. "Combustion an Attrition of biomass Chars in a Fluidized Bed". Energy and Fuels, 2006

[5] B. Leckner, K. Hanason, C. Tullin, A.V. Borodulya, V. Dikalenko- Kinetics fluidized bed combustion of wood pellets. Reuter RB, ed. 15th Int. Conf. on Fluidized Bed Combustion, vol. Paper FBC99-0047 Paper FBC99-0047 Savannah: ASME, 1999.

[6] Leckner B, Palchonok G, Borodulya VA, Tullin C, Samuelsson J. Influence of attrition on combustion of biomass pellet char. In: Salatino P., ed. International Energy Agency Workshop, Attrition Phenomena in Fluidized Bed Conversion University of Salerna, Italy, 2000.

[7] Moreno, R.; Rios, .R. "Study of sawdust drying techniques in fluidized bed". Engineering, 2002- 82(3).

[8] Stubington,J.F; Davidson,J.F. "Gas phase combustion in fluidized beds”. A.I.Ch.E. journal, 27,59, 1981. 